Forum Presentation

\title{
The Role of Tissue Factor in the Pathogenesis of Thrombosis and Atherosclerosis
}

\author{
Yujiro Asada, Kousuke Marutsuka, Kinta Hatakeyama, Yuichiro Sato, Seiichiro Hara, \\ Atsushi Kisanuki, and Akinobu Sumiyoshi
}

1st Department of Pathology, Miyazaki Medical College, Miyazaki, Japan.

\begin{abstract}
TF is a major regulator of coagulation and hemostasis. High levels of TF antigen and activity are detected in atherosclerotic lesions, particularly in the advanced lesions. When the plaques are ruptured or eroded, exposure of cellular and extracellular TF to circulating blood play a pivotal role in mediating fibrin-rich thrombus formation leading to acute coronary syndromes. On the other hand, activation of blood coagulation and deficiency of coagulation inhibitors, without endothelial cell denudation, are considered to be an important factor of thrombogenesis in the microcirculation. The imbalance between TF and TFPI seems to be important in promoting fibrin thrombus formation in the lung of endotoxin induced DIC condition. J Atheroscler Thromb, $1998 ; 4$ : 135-139.
\end{abstract}

Key words : Tissue factor, Thrombosis, Atherosclerosis, DIC

\section{Introduction}

Endothelial cells modulate several aspects of the hemostasis-coagulation sequence, and possess antiplatelet, anticoagulant, and fibrinolytic properties (1). On the other hand, when they are injured or activated, they may exert procoagulant functions. Thrombosis is considered to occur when the balance between thrombotic factors and endothelial protective mechanisms is broken out.

The thrombogenic factors are as follows; 1) perturbation of endothelial cells, 2) loss of endothelial cells with exposure of subendothelium, 3) activation of platelets by their interaction with subendothelial collagen or circulating agonists, 4) activation of blood coagulation, 5) inhibition of fibrinolysis, and 6) stasis. In these factors, however, loss of endothelial cells is essential in thrombo-

Address for correspondence: Yujiro Asada, 1st Department of Pathology, Miyazaki Medical College, Miyazaki 889-1692, Japan.

This article is presented in the Forum \#5 on Molecular Biology and Pathology of Thrombosis at the 29th Annual Meeting on the Japan Atherosclerosis Society in Tokyo, 1997.

Received February 12, 1998. genesis in the arteries, while the activation of blood coagulation mainly due to deficiency of coagulation inhibitors is considered to be an important factor in the microcirculation.

Tissue factor (TF) initiates the extrinsic coagulation cascade and is a major regulator of coagulation, hemostasis, and thrombosis. TF is a $47-k D$ transmembrane glycoprotein and a specific cofactor for plasma coagulation factor VII/VIla. Although native TF itself has no intrinsic protease activity, the bimolecular complex of TF and factor VII/VIla results in catalytic enhancement of the factor VIla catalytic domain and activates factors IX and X thereby leading to thrombin generation $(2,3)$. In normal vessels, TF is present only in the adventitia $(4,5)$. Recent studies show that TF is overexpressed in atherosclerotic lesions and contributes to the plaque thrombogenicity (6-11).

We examined the role of TF in thrombogenicity of the atherosclerotic lesions of human and an animal model, and in the endotoxin-induced DIC model.

\section{TF in Human Atherosclerotic Lesions}

The critical event converting asymptomatic atherosclerotic lesions into symptomatic ones is considered to be thrombosis. Plaque rupture or fissure is the most fre- 


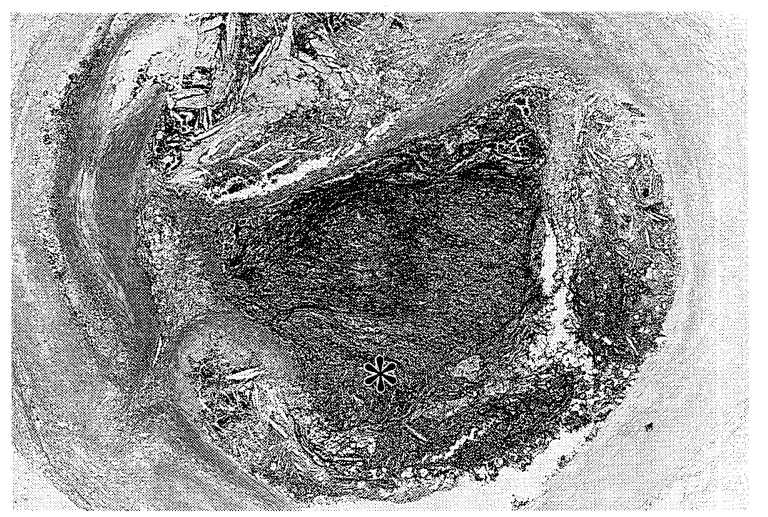

Fig. 1. Fresh thrombus of the right coronary artery observed in a 56-year-old woman died 2 hours after the onset of arrhythmia. Plaque rupture (asterisk) with an occlusive thrombus is present. The plaque contains a large lipid core and dense infiltrate of foamy macrophages is noted in the fibrous cap. (Mallory-azan, $\times 30$ )

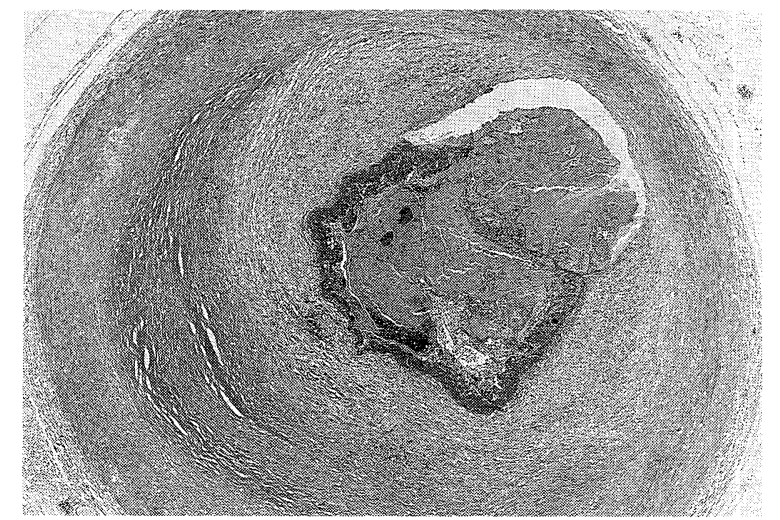

Fig. 2. Almost occlusive thrombus of the right coronary artery noted in a 49 -year-old man died 4 hours after complaining of chest pain. The eccentric fibrous plaque is rich in SMCs and proteoglycans. No lipid core is present. The luminal surface is eroded. (H.E., $\times 30)$

quent cause of coronary thrombosis and in the clinical presentation of acute coronary syndromes $(12,13)$. Fibrin-rich large thrombi were very frequently observed on and in the ruptured plaques (Fig. 1). Atherosclerotic plaques that are vulnerable to rupture have a dense infiltrate of macrophages and, to a lesser extent, lymphocytes within a fibrous cap overlying a crescentic acellular mass of lipids (13). Plaque erosion has recently been identified as the another mechanism of coronary thrombosis, and is an important cause of sudden coronary death (14). In contrast with ruptured plaques, eroded plaques are rich in smooth muscle cells (SMCs) and proteoglycans and are lacking a superficial lipid core (Fig. 2). Although plaque rupture is more common than plaque erosion as a cause of major thrombi, it has been reported that, in an autopsy study of sudden cardiac death, culprit thrombi were frequently ( $>40 \%$ ) found on eroded plaques

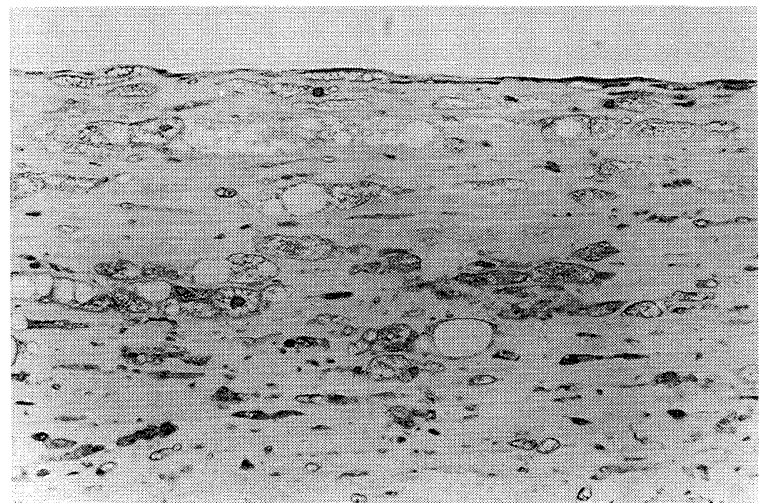

Fig. 3. Immunohistochemical staining of TF in human aortic atheorsclerotic lesion. Many macrophages and SMCs show positive reaction for TF. Endothelial cells on the lesion are scatteredly positive for TF. $(\times 300)$

(14). Additionally, in women who died suddenly of ischemic heart disease, $69 \%$ of the thrombi were due to plaque erosion (14).

High levels of TF antigen, mRNA, and activity have been detected in atherosclerotic plaques obtained by human atherectomy of the carotid and coronary arteries $(6,7)$. Additionally it has been recently reported that higher levels of TF antigen were observed in coronary atherectomy specimens from patients with unstable angina than with stable angina (8). The immunohistochemical studies revealed that TF antigen was present in macrophages, SMCs, and the extracellular matrix, most intensely in cholesterol crystal-rich areas of the plaques $(6,7)$.

In our study (11), TF antigen was detected in the various stages of atherosclerotic lesions (diffuse intimal thickening, fatty streak, and atheromatous plaque). In diffuse intimal thickening, almost all of the intimal SMCs were positive for TF. In fatty streaks, many foamy macrophages were positively stained for TF (Fig. 3). In atheromatous plaques, TF antigen was extensively observed extracellularly as well as in the intimal cells. TF-positive cells were mainly SMCs in the fibrous cap and were macrophages in the shoulder areas of the plaques. Additionally TF activity was detected by a chromogenic assay using S-2222, and was higher in the fatty streaks and the atheromatous plaques than in the diffuse intimal thickening. These results indicate that TF detected immunohistochemically in the lesions is biologically active. Prominent TF expression in the advanced lesions is considered to contribute to thrombus formation on plaque rupture. In addtion, exposing active TF of intimal SMCs to circulating blood could become the trigger of acute thrombosis on plaque erosion.

On the other hand, a monolayer or small aggregates of platelets without fibrin were occasionally observed on the de-endothelialized areas of the fibrous cap. These areas 


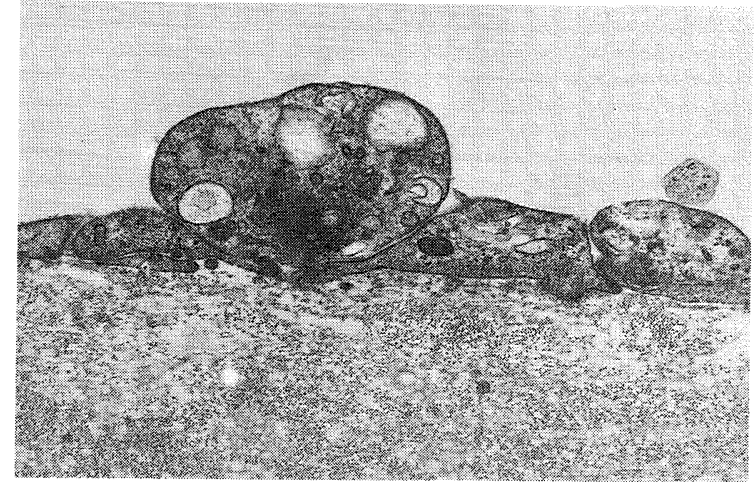

Fig. 4. Transmission electron micrograph of a surface of human aortic plaque. Adhesion and aggregate of platelets are observed at the de-endothelialized area. The subendothelium is rich in collagen bundles and lacking cellular elements. $(\times 18,000)$

were rich in collagen bundles but lacking cellular elements or superficial lipid core (Fig. 4). The evidence suggests that the exposure of cellular and extracellular TF to circulating blood is of great significance for thrombin generation and fibrin-rich thrombus formation on the plaques.

\section{Thrombus Formation on the Neointima in Animal Models}

Thrombus formation is commonly associated with acute arterial injury. Fibrin generation and thrombus formation on the injured vessel are natural consequences after balloon angioplasty, directional atherectomy, or arterial stenting. Therefore, the study of responses of diseased vessels to injury is relevant to the thrombus formation and restenosis after angioplasty in the clinical setting.

It is well known that superficial injury (endothelial denudation without medial injury) of normal arteries is associated with platelet adhesion on the subendothelium without fibrin generation (15), while several reports showed that fibrin deposition was induced on the injured neointima (16-18). We examined thrombus formation following the second balloon injury to the rabbit aorta injured 4 weeks earlier (19). The neointima 4 weeks after the first balloon injury was composed exclusively of SMCs and almost all of these SMCs were immunohistochemically positive for TF antigen. This finding is similar to that of human diffuse intimal thickening. In this study, two kinds of thrombus (platelet-rich and fibrin-rich) were induced on the injured surface of the rabbit neointima. Platelet-rich thrombi were formed on the mildly injured neointima, in which the connective tissue was mainly exposed without intimal SMC damage, whereas fibrin-rich large thrombi were formed on the severely injured neointima associated with obvious damage of intimal SMCs. This evidence indicates that the exposure of TF derived from the

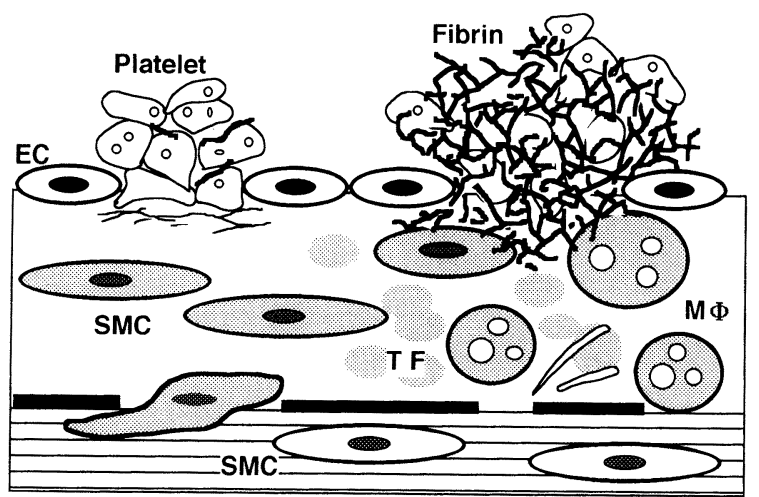

Fig. 5. Schema of platelet- and fibrin-rich thrombus formation. TF is present in macrophages and intimal SMCs, and in the extracellular matrix of the advanced lesion. Exposure of cellular and/or extracellular TF to circulating blood initiates the thrombin generation and fibrin deposition. (EC : endothelial cell, $M \varnothing$ : macrophage)

damaged intimal SMCs may contribute to the initiation of the coagulation pathway, leading to the thrombin generation and fibrin formation (Fig. 5).

Thrombi have long been implicated in the formation of the neointima. Much of the neointimal volume appears to be related to the early fibrin-rich mural thrombi, and fibrin thrombi were found to be important in restenosis because they provided volume into which SMC migrated and for SMC proliferation $(20,21)$. Fibrin and fibrin fragments are chemotactic for SMCs in vitro (22), and thrombin has been shown to activate platelets and stimulate SMC proliferation (23). In addition, we have recently demonstrated that the migration of the cultured aortic SMCs was induced by a complex of TF-factor VIla (24). Therefore, TF seems to affect the neointimal development through direct or indirect action on SMCs. These findings support the possibility that TF in the intima plays an important role in the development and progression of atherosclerosis as well as in thrombus formation.

\section{TF in LPS-induced DIC Model}

Disseminated intravascular coagulation (DIC) is a frequent complication of endotoxin shock, and modulation of endothelial cell hemostatic properties has been proposed to play an important role in its onset. The trigger mechanisms of DIC in sepsis are not fully understood but endotoxin is considered to play an important role in them (25, 26). In recent clinical studies, a significant role of plasma TF has been suggested in the pathogenesis of DIC (26-28), and high levels of plasma TF activity in DIC rats have also been reported (29). The origin of plasma TF increased in DIC patients remains to be clarified. Possible cells are monocytes and endothelial cells. TF is not normally present in these cells, but on stimulation with a variety of inflammatory agents such as lipopolysaccharide 
(LPS), interleukin-1, and tumor necrosis factor- $\alpha$, these cells can synthesize and express TF on their surfaces in the culture system (3). However, whether endothelial cells can express TF in vivo remains controversial.

Tissue factor pathway inhibitor (TFPI) is a Kunitz-type protease inhibitor that directly inhibits factor $\mathrm{Xa}$ and produces a feedback inhibition of the TF-factor VIla catalytic complex in a factor Xa-dependent manner (30). TFPI is considered to be one of the most important physiological inhibitors in vivo among the known inhibitors of TF-dependent coagulation. It has been reported that TFPI was present on the surface of microvascular endothelial cells and in megakaryocytes (31). Recently a few clinical studies examined the plasma TFPI level in DIC patients, but the relationship with the prognosis of DIC is still unclear $(32,33)$. On the other hand, the role of TFPI against endotoxin-induced DIC has been emphasized in the several studies using DIC animal models (3437).

We examined the expression of TF and TFPI in rat lungs of a LPS-induced DIC model (38). Light and electron microscopic studies showed that fibrin-rich thrombi were present in the pulmonary microvasculature 3 hours after intraperitoneal injection of LPS $(7.5 \mathrm{mg} / \mathrm{kg})$ and increased in number at 6 hours. Monocytes in the microvasculature increased in number following LPS injection and many of these cells ( $>90 \%$ ) were immunohistochemically positive for TF antigen. However, no TF expression in endothelial cells was detected. Pulmonary endothelial cells showed positive reaction for TFPI antigen before LPS injection, but TFPI-positive endothelial cells markedly decreased in number after LPS injection. mRNA expression of TF increased and that of TFPI decreased in the lung tissue after LPS injection. High values of TF activity were detected in the lung tissue and plasma, whereas TFPI activities decreased after LPS injection.

The results of previous and the present studies indicate that the imbalance between TF and TFPI seems to be important in promoting fibrin thrombus formation in the lung under a certain condition such as a fulminant endotoxin influx into the blood circulation.

\section{References}

(1) Bombeli T, Mueller M, and Haeberil A: Anticoagulant properties of the vascular endothelium. Thromb Haemost, $77:$ 408-423, 1997

(2) Nemerson $Y$ : Tissue factor and hemostasis. Blood, 71 : 1-8, 1988

(3) Camerer E, Kolst $\varnothing \mathrm{A}-\mathrm{B}$, and Prydz $\mathrm{H}$ : Cell biology of tissue factor, the principal initiator of blood coagulation. Thromb Res, 81: 1-41, 1996

(4) Drake TA, Morrissey JH, and Edgington TS: Selective cellular expression of tissue factor in human tissues. Am J Pathol, 134 : 1087-1097, 1989

(5) Fleck RA, Rao LVM, Rapaport SI, and Varki N : Localization of human tissue factor antigen by immunostaining with monospecific, polyclonal antihuman tissue factor antibody. Thromb Res, $57:$ 765-781, 1990

(6) Wilcox JN, Smith KM, Schwartz SM, and Gordon D: Localization of tissue factor in the normal vessel wall and in the atherosclerotic plaque. Proc Natl Acad Sci USA, 86: 2839-2843, 1989

(7) Marmur JD, Thiruvikraman SV, Fyfe BS, Guha A, Sharma SK, Ambrose A, Fallon JT, Nemerson Y, and Taubman MB: Identification of active tissue factor in human coronary atheroma. Circulation, 94: 1226-1232, 1996

(8) Annex BH, Denning SM, Channon KM, Sketch MH Jr, Stack RS, Morrissey JH, and Peters KG: Differential expression of tissue factor protein in directional atherectomy specimens from patients with stable and unstable coronary syndromes. Circulation, 91: 619-622, 1995

(9) Kato K, Elsayed YA, Namoto M, Nakagawa K, and Sueishi K : Enhanced expression of tissue factor activity in the atherosclerotic aortas of cholesterol-fed rabbits. Thromb Res, 82 : 335-347, 1996

(10) Thiruvikraman SV, Guha A, Roboz J, Taubman MB, Nemerson $Y$, and Fallon JT : In situ localization of tissue factor in human atherosclerotic plaques by binding of digoxigenin-labeled factors VIla and X. Lab Invest, 75 : 451-461, 1996

(11) Hatakeyama K, Asada Y, Marutsuka K, Sato Y, Kamikubo $Y$, and Sumiyoshi A : Localization and activity of tissue factor in human aortic atherosclerotic lesions. Atherosclerosis, 133: 213-219, 1997

(12) Goldberg ID and Rosen EM : Hepatocyte Growth FactorScatter Factor (HGF-SF) and C-met receptor. Birkhauser Verlag, Basal : 225-249, 1993

(13) Davies MJ: The contribution of thrombosis to the clinical expression of coronary atherosclerosis. Thromb Res, 82 : 1-132, 1996

(14) Farb A, Burke AP, Tang AL, Liang Y, Mannan P, Smialek $\mathrm{J}$, and Virmani $\mathrm{R}$ : Coronary plaque erosion without rupture into a lipid core: A frequent cause of coronary thrombosis in sudden coronary death. Circulation, 93 : 1354-1363, 1996

(15) Ferns GAA, Stewart-Lee AL, and Änggård EE : Arterial response to mechanical injury: balloon catheter deendothelialization. Atherosclerosis, 92: 89-104, 1992

(16) Groves HM, Kinlough-Rathbone RL, Richardson M, Jørgensen L, Moore S, and Mustard JF : Thrombin generation and fibrin formation following injury to rabbit neointima: studies of vessel wall reactivity and platelet survival. Lab Invest, 46: 605-612, 1982

(17) Jørgensen L, Grøthe AG, Groves HM, Kinlough-Rathbone $\mathrm{RL}$, Richardson M, and Mustard JF : Distribution of cellular responses in rabbit aortae following one and two injuries with a balloon catheter. $\mathrm{Br} J$ Exp Pathol, 69 : 351-365, 1988

(18) Jørgensen L, Grøthe AG, Groves HM, Kinlough-Rathbone $\mathrm{RL}$, Richardson M, Mustard JF : Sequence of cellular responses in rabbit aortae following one and two injuries with a balloon catheter. $\mathrm{Br} J$ Exp Pathol, 69 : 473-486, 1988

(19) Asada Y, Hara S, Tsuneyoshi A, Hatakeyama K, Kisanuki A, Marutsuka K, Sato Y, Kamikubo Y, and Sumiyoshi A : Fibrin-rich or platelet-rich thrombus formation on neointima: recombinant tissue factor pathway inhibitor prevents fibrin formation and neointimal development following secondary balloon injury to previously induced 
rabbit aortic neointima. (submitted)

(20) Schwartz CJ, Valente AJ, Kelley JL, Sprague EA, and Edwards EH: Thrombosis and the development of atherosclerosis: Rokitansky revisited. Semin Thromb Hemost, 14 : 189-195, 1988

(21) Schwartz RS, Holmes DR Jr, and Topol EJ: The restenosis paradigm revisited: An alternative proposal for cellular mechanisms. J Am Coll Cardiol, 20: 12841293, 1992

(22) Smith EB and Thompson WD: Fibrin as a factor in atherogenesis. Thromb Res, 73: 1-19, 1994

(23) Turpie AGG, Weitz Jl, and Hirsh J: Advances in antithrombotic therapy: Novel agents. Thromb Haemost, 74: 565-571, 1995

(24) Sato Y, Asada Y, Marutsuka K, Hatakeyama K, Kamikubo $Y$, and Sumiyoshi $A$ : Tissue factor pathway inhibitor inhibits aortic smooth muscle cell migration induced by tissue factor/factor VIla complex. Thromb Haemost, 78 : 1138-1141, 1997

(25) Levi M, Ten Cate H, van der Poll T, and van Deventer SJH : Pathogenesis of disseminated intravascular coagulation in sepsis. JAMA, 270: 975-979, 1993

(26) Asakura H, Kamikubo Y, Goto A, Shiratori Y, Yamazaki M, Jokaji H, Saito M, Uotani C, Kumabashiri I, Morishita E, Aoshima K, Nakamura S, and Matsuda T: Role of tissue factor in disseminated intravascular coagulation. Thromb Res, 80: 217-224, 1995

(27) Takahashi H, Satoh N, Wada K, Takakuma E, Seki Y, and Shibata A: Tissue factor in plasma of patients with disseminated intravascular coagulation. Am J Hematol, 46: 333-337, 1994

(28) Koyama T, Nishida K, Ohdama S, Sawada M, Murakami N. Hirosawa S, Kuriyama R, Matsuzawa K, Hasegawa R, and Aoki $\mathrm{N}$ : Determination of plasma tissue factor antigen and its clinical significance. $\mathrm{Br} \mathrm{J}$ Haematol, 87 : 343-347, 1994

(29) Kawamura M, Terashita Z, Imura Y, Shino A, and Nishikawa K: Inhibitory effect of TCV-309, a novel platelet activating factor (PAF) antagonist, on endotoxininduced disseminated intravascular coagulation in rats: Possible role of PAF in tissue factor generation. Thromb
Res, $70: 281-293,1993$

(30) Broze GJ Jr: Tissue factor pathway inhibitor. Thromb Haemost 74: 90-93, 1995

(31) Petersen LC, Valentin S, and Hedner U : Regulation of the extrinsic pathway system in health and disease: The role of factor VIla and tissue factor pathway inhibitor. Thromb Res, 79: 1-47, 1995

(32) Shimura M, Wada H, Wakita $Y$, Nakase T, Hiyoyama K, Nagaya $S$, Mori $Y$, and Shiku $H$ : Plasma tissue factor and tissue factor pathway inhibitor levels in patients with disseminated intravascular coagulation. Am J Hematol, 52: 165-170, 1996

(33) Weissbach G, Herenberg J, Wendisch J, Pargec N, and Thomas $\mathrm{K}$ : Tissue factor pathway inhibitor in infants and children. Thromb Res, 73: 441-446, 1994

(34) Bregengård $\mathrm{C}$, Nordfang $\mathrm{O}$, Wildgoose $\mathrm{P}$, Svendsen $\mathrm{O}$, Hedner $U$, and Diness $V$ : The effect of two-domain tissue factor pathway inhibitor on endotoxin-induced disseminated intravascular coagulation in rabbits. Blood Coag Fibrinol, 4 : 699-706, 1993

(35) Creasey AA, Chang ACK, Feigen L, Wün TC, and Taylor FB. Tissue factor pathway inhibitor reduces mortality from Escherichia coli septic shock. J Clin Invest, 91 : 2850-2860, 1993

(36) Day KC, Hoffman LC, Palmier MO, Kretzmar KK, Huang MD, Pyla EY, Spokas E, Broze GJJr, Warren TG, and Wun TC: Recombinant lipoprotein-associated coagulation inhibitor inhibits tissue thromboplastin-induced intravascular coagulation in the rabbit. Blood, 76 : 1538-1545, 1990

(37) Elsayed YA, Nakagawa K, Kamikubo Y, Enjyoji K, Kato $\mathrm{H}$, and Sueishi $\mathrm{K}$ : Effects of recombinant human tissue factor pathway inhibitor on thrombus formation and its in vivo distribution in a rat DIC model. Am J Clin Pathol, 106: $574-583,1996$

(38) Hara S, Asada Y, Hatakeyama K, Marutsuka K, Sato Y, Kisanuki A, and Sumiyoshi A: Expression of tissue factor and tissue factor pathway inhibitor in rat lungs with lipopolysaccharide-induced disseminated intravascular coagulation. Lab Invest, 121: 45-53, 1997 